\title{
Studies on the equine placenta III. Ultrastructure of the uterine glands and the overlying trophoblast
}

\author{
Carole A. Samuel, W. R. Allen* and D. H. Steven \\ Department of Anatomy, University of Cambridge, and *A.R.C. Animal Research Station, \\ 307 Huntingdon Road, Cambridge, U.K.
}

\begin{abstract}
Summary. Ultrastructural studies of the uterine glands at intervals during pregnancy in the mare show that secretory activity continues after formation of the placental exchange units. The nature of the glandular secretion appeared initially to be proteinaceous, but cellular debris was also present during the last third of gestation. These secretions were absorbed by the trophoblast overlying the mouths of the glands. The fate of the secretions and their significance for the fetus and placenta are unknown.
\end{abstract}

\section{Introduction}

The uterine glands of the mare are blind tubular structures which lie within the uterine stroma approximately at right angles to the surface epithelium. Each gland consists of a short narrow duct, a straight tubular region of larger calibre, and a predominantly secretory region which is deeply situated and highly coiled. The glands, which are usually arranged in groups of four, empty their secretions into shallow depressions in the uterine surface. When the microcotyledons, which constitute the areas of placental gas exchange (Samuel, Allen \& Steven, 1976), are formed, the openings of the glands lie between them.

Interest in the cytology of the uterine glands in the mare has so far been overshadowed by the greater interest directed towards the placental barrier itself. Only Kolster (1902) and Amoroso (1952) have drawn attention to the possible importance in the horse of the uterine glands and their secretions. We have now used ultrastructural techniques to investigate the structure and activity of these glands at known stages of pregnancy. The results of this work have been briefly reported (Samuel \& Steven, 1976).

\section{Materials and Methods}

Samples of placenta and uterus were obtained from Welsh Mountain Pony mares at 46, 61, 75, 98, $101,150,200,250$ and 300 days of pregnancy. All samples were prepared for electron microscopy by the method described previously (Samuel, Allen \& Steven, 1974). Specimens were examined with a Philips 300 electron microscope. Specimens for histochemistry were obtained at autopsy from Dartmoor Pony mares at 106, 264 and 278 days of gestation and frozen immediately in liquid nitrogen. The presence of acid phosphatase activity was detected in $15-\mu \mathrm{m}$ frozen sections with the adaptation of the Gomori method described by Chayen, Bitensky \& Butcher (1973) in which sodium- $\beta$ glycerophosphate was used as the substrate.

\section{Observations and Discussion}

Many changes in the size and ultrastructure of the secretory cells of the uterine glands were noted (see Text-fig. 1). The uterine glands secreted actively throughout pregnancy and the overlying chorionic epithelium contained inclusions resembling the secretory product. 


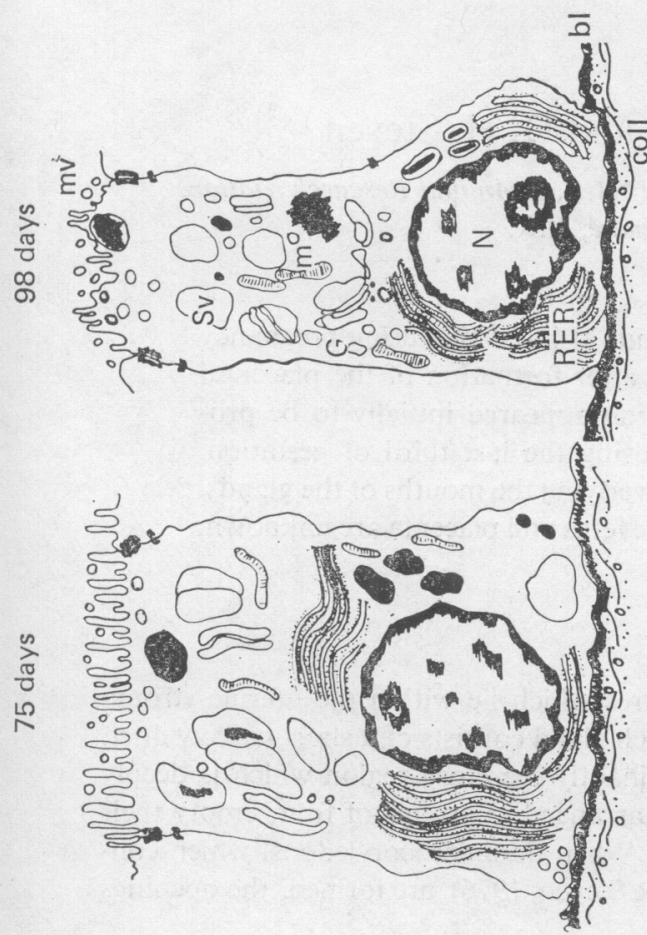

त्र

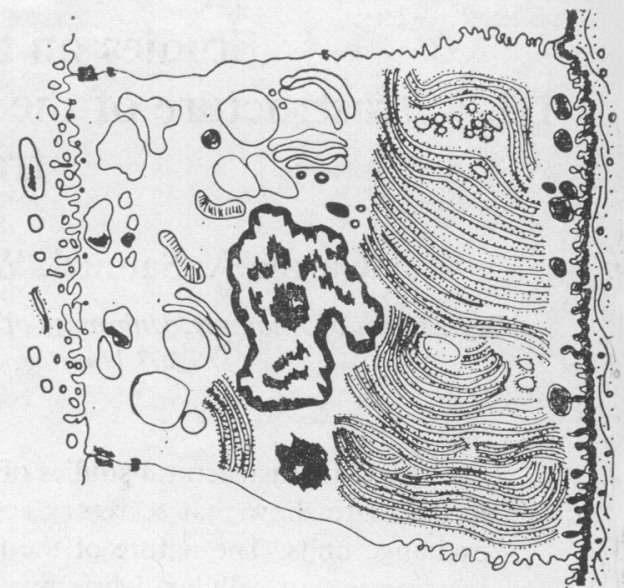

- $).$

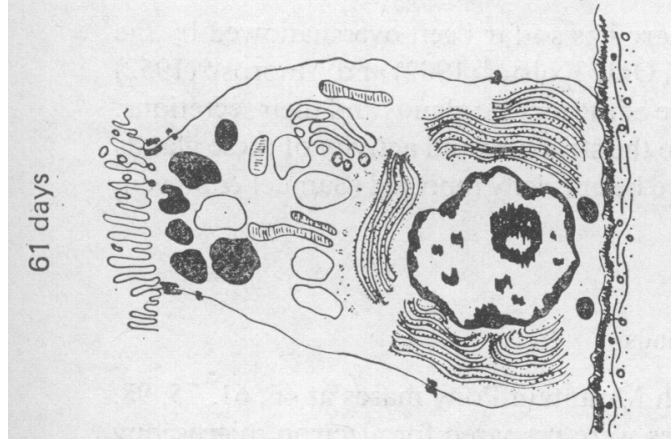

กับ

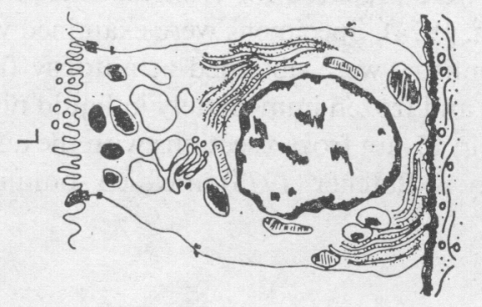

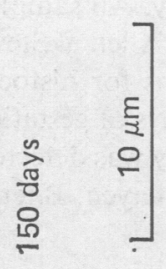




\section{Uterine glands}

Days 46, 61 and 75 (Pl. 1, Fig. 1). The secretory epithelium, which rested upon a well defined basal lamina, consisted of tall, slightly tapering, columnar cells joined at their apices by junctional complexes. The luminal surface was covered by small microvilli. Large euchromatic nuclei with smooth outlines were located basally and surrounded luminally and laterally by rough endoplasmic reticulum (RER). Many Golgi elements were observed immediately above the nucleus and GERL (Golgi-endoplasmic reticulum-lysosome complex) membranes were tentatively identified. The apical cytoplasm was filled with membrane-bound structures of variable size and electron-density, while small coated vesicles were observed close to the Golgi regions. Large clear vesicles were present in the apical regions of the cells towards the end of this period, but electron-dense inclusions were more common at 46 days of gestation. Vesicles appeared to have fused with the plasmalemma and discharged their contents into the gland lumen. Small vermiform mitochondria were seen in the region of the RER. The lateral and basal plasma membranes were smooth.

Days 98, 101 and 150. During this period an increase of some $50 \%$ was observed in the height of the secretory cells. The RER became more prominent and occupied a greater part of the cell volume than earlier in gestation, while the cisternae were slightly distended with an homogeneous material (Pl. 1, Fig. 2). The Golgi regions of the cells were large but ill-defined, being surrounded by many large vesicles. These vesicles were observed in contact with the apical borders of the cells and also discharging into the gland lumen. The lumina of the glands were filled with a dense flocculent material closely resembling that in the apical vesicles. Close to the nuclei, membrane-bound crystalline inclusions, which took the form of extremely electron-dense, straight, hollow tubes, were observed (Pl. 1, Fig. 3). Convolutions of the lateral membranes and enlarged intercellular spaces were present in the basal regions of the cells.

Days 200, 250 and 300. The increase in secretory material in the apices of the cells, previously observed at 150 days, was continued throughout the last third of gestation. The large vesicles emptied into the gland lumen which was filled with a flocculent secretion (Pl. 1, Fig. 4). During this period of gestation the number of degenerate cells in the secretory epithelium increased, and cellular debris was observed in the secretion of the glands (Pl. 1, Fig. 5). By 200 days the ratio of nuclear to cytoplasmic volume, as estimated from measurements of area on electron micrographs, decreased as the nuclei became smaller and more irregular in profile. The RER was more prominent than earlier in gestation as it was found in the area basal to the nuclei as well as lateral and apical to them. This increase in RER resulted in apparent movement of the nuclei towards the apex of the cells (Pl. 1, Fig. 6).

Activity of the secretory epithelium of the uterine glands was observed throughout pregnancy, although the nature of the secretion varied. The flocculent appearance of the secretion early in pregnancy suggested the presence of a protein or glycoprotein, corresponding well with previous observations (Amoroso, 1952). The cellular debris in the secretion later in pregnancy is in accordance with an early description of holocrine secretion of this kind by Kolster (1902).

Histochemical investigations of acid phosphatase activity of the Golgi and GERL regions during secretion (see Novikoff \& Novikoff, 1976) showed intense deposition of reaction product in the apical regions of the secretory cells during early (106 days) and late (264 and 278 days) stages of pregnancy. These observations support the belief that secretions are being produced throughout gestation.

\section{The ducts and overlying chorionic epithelium}

The epithelium lining the short duct regions of the glands showed little structural differentiation from the secretory epithelium except that the overall height of the cells was lower when micrographs

Text-fig. 1. Diagrammatic generalizations of the uitrastructure of the secretory cells of the uterine glands of the mare during the stages of pregnancy indicated. bl, Basal lamina; coll, collagen fibres; G, Golgi apparatus; $L$, lumen of gland; $m$, mitochondrion; $\mathrm{mv}$, microvilli; $\mathrm{N}$, nucleus; $R \mathrm{ER}$, rough endoplasmic reticulum; Sv, secretory vesicles. 
were measured and compared. Nevertheless, the changes observed during pregnancy in the secretory epithelium were reflected in the duct regions. Ciliated cells were found in the secretory and duct epithelia, although more frequently in the latter, and contained secretory vesicles as well as the sub-membrane complexes associated with cilia (Pl. 1, Fig. 7).

The duct regions of the glands merged smoothly into the uterine epithelium forming the depressions between the microcotyledons into which the secretions were exuded, presumably aided by ciliary action. The chorionic epithelium overlying the depressions in the uterine epithelium was characterized by large columnar cells filled with irregular dense inclusions (Pl, 1, Fig. 8). These cells were joined laterally by junctional complexes but the apical regions of the cells, covered with irregular microvilli, projected greatly beyond the level of these complexes. The lateral walls of the intercotyledonary chorionic epithelial cells were separated by intricate intercellular spaces. Micropinocytotic vesicles of all dimensions were observed in the apical prominences and frequently contained dense material like that in the gland ducts and intercotyledonary depressions. Larger membrane-bound inclusions filled the more basal regions of the cells above and around the nuclei. Both RER and Golgi regions were observed in the supranuclear area, and lysosome-like bodies arose from them and united with the dense membrane-bound bodies.

Degradation bodies containing myelin figures were observed. Acid phosphatase activity was present in the intercotyledonary regions of the chorionic epithelium early and late in gestation, although its demonstration required a longer incubation than that in the secretory cells. This activity was almost certainly associated with the lysosome particles and absorptive nature of the chorionic cells, confirming the view that the intercotyledonary areas of the equine placenta are similar to the areolae in the porcine placenta, forming regions where the secretions of the uterine glands are absorbed by the chorionic epithelium (see Crombie, 1972). The fetal capillaries in these intercotyledonary regions do not become intraepithelial, as in the microcotyledons, but remain below the base of the epithelium.

The significance of the secretions of the uterine glands in the economy of the fetus and placenta has been a subject for discussion since Bonnett (1882) concluded that, in ruminants, the uterine gland secretions were very important to the well-being of the fetus. The presence of well differentiated areas of the equine placenta capable of absorbing and breaking down the secretions of the uterine glands suggests that Bonnett's conclusions may be extended to this species also. Further experimental work is required to determine the nature of the secretion and the fate of its components in the growing fetus and placenta.

This work was supported by the Thoroughbred Breeders' Association, the Medical and Agricultural Research Councils and the Wellcome Trust. We are most grateful to Mr L. E. A. Rowson, F.R.S., for assistance with the surgery; to the staff of the A.R.C. Unit of Reproductive Physiology and

\section{EXPLANATION OF PLATE}

Abbreviations: C, crystalline inclusion; D, electron-dense inclusion; G, Golgi apparatus; GERL, Golgiendoplasmic reticulum lysosome complex; ICT, intercotyledonary trophoblast; L, lumen of gland; $\mathrm{m}$, mitochondrion; ME, maternal epithelium; N, nucleus; RER, rough endoplasmic reticulum; S, secretion; $\mathrm{Sv}$, secretory vesicles.

Fig. 1. Secretory cells from the uterine glands of a mare at 61 days of gestation.

Fig. 2. Supranuclear region of a secretory cell from a uterine gland of a mare at 98 days of gestation.

Fig. 3. Basal region of secretory cells at 98 days of gestation.

Fig. 4. Apices of secretory cells at 200 days of gestation.

Fig. 5. Cellular debris found in gland lumen at 200 days of gestation.

Fig. 6. Secretory cells at 250 days of gestation.

Fig. 7. Ciliated cell from duct region of uterine gland at 75 days of gestation.

Fig. 8. Chorionic epithelium overlying the mouth of a gland at 75 days of gestation. 
PLATE 1
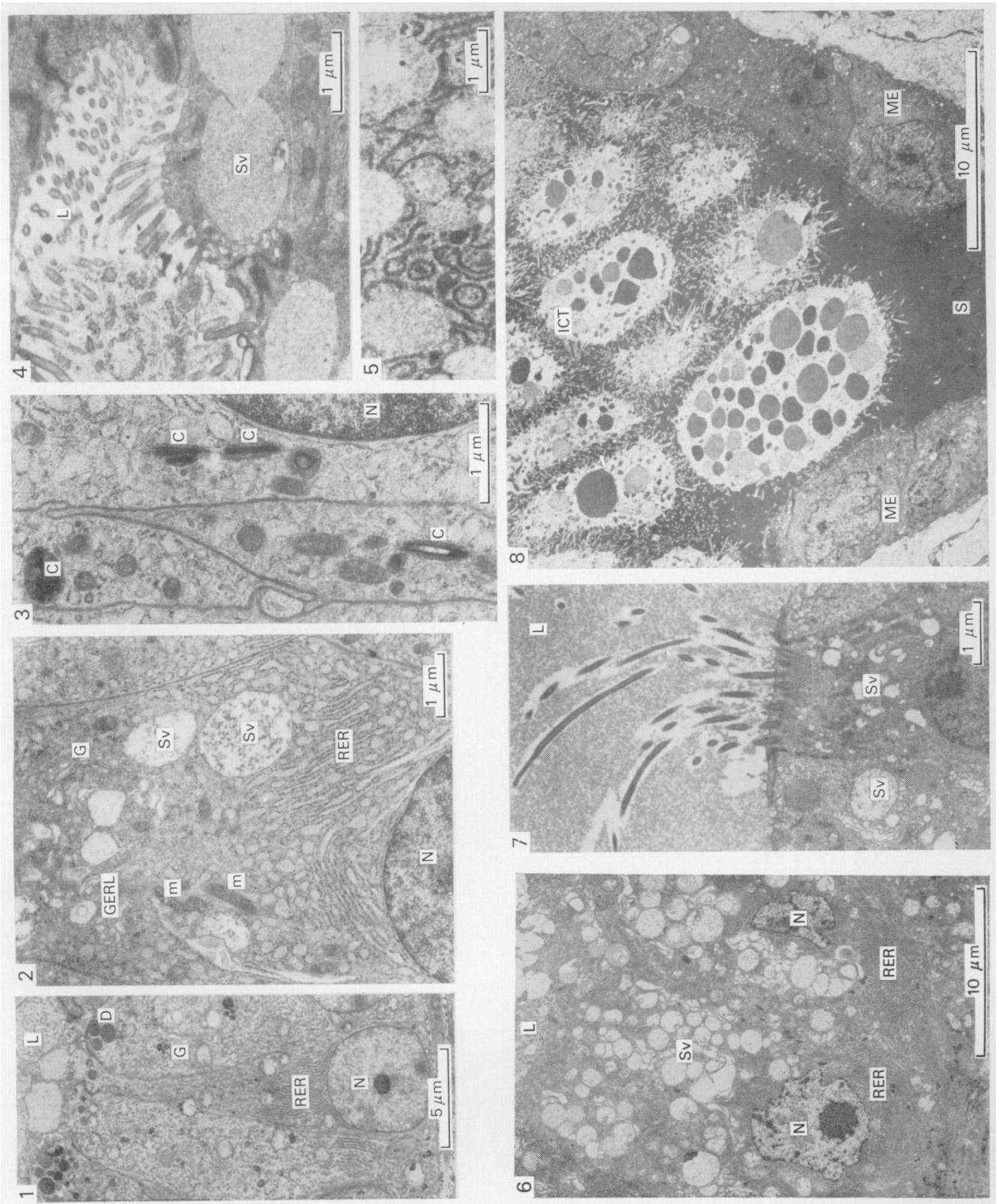
Biochemistry and the electron microscopy and audio-visual aids sections of the Department of Anatomy; to Miss K. Mallon for technical assistance and to Mrs M. Craig and Mrs D. W. Candy for typing the manuscripts. We thank Dr I. W. Rowlands for constructive criticism of the text, and Dr P. F. Flood for supplying the material for histochemistry.

\section{References}

Amoroso, E.C. (1952) Placentation. In Marshall's Physiology of Reproduction, 3rd edn, Vol. 2, pp. 127-311. Ed. A. S. Parkes. Longmans Green, London.

BONNETT, R. (1882) Die Uterinmilch und ihre Bedeutung für die Fruct. Beiträge zur Biologie als Festgabe dem Anatomen und Physiologen, pp, 221-263. Th. von Bischoff, Stuttgart.

Chayen, J., Bitensky, L. \& Butcher, R. (1973) Practical Histochemistry, pp. 128-130. John Wiley \& Sons, London.

Crombie, P.R. (1972) The morphology and ultrastructure of the pig's placenta throughout pregnancy. Ph.D. thesis, University of Cambridge.

KolsTER, R. (1902) Die Embryotrophe placentarer
Säuger mit besonderer Berucksichtigung der Stute. Arb. anat. Inst., Wiesbaden 18, 455-505.

NovikofF, A.B. \& NovikofF, P.M. (1976) Cytochemical studies on Golgi apparatus and GERL in insulinoma, exocrine pancreas and hepatocytes. Proc. $R$. microsc. Soc. 11, 22, Abstr.

SAmuel, C.A. \& SteVEN, D.H. (1976) Uterine gland secretions in the economy of fetus and placenta. J. Anat. 122, 720-722.

Samuel, C.A., Allen, W.R. \& Steven, D.H. (1974) Studies on the equine placenta. I. Development of the microcotyledons. J. Reprod. Fert. 45, 441-445.

Samuel, C.A., Allen, W.R. \& Steven, D.H. (1976) Studies on the equine placenta. II. Ultrastructure of the placental barrier. J. Reprod. Fert. 48, 257-264.

Received 4 April 1977 